\title{
The Mental Health Act and Public Perception on Resource Allocation in Bangladesh
}

\author{
Md. Sanwar Siraj ${ }^{1, ~ *, ~ R e b e c c a ~ S u s a n ~ D e w e y ~}{ }^{2}$, Md Ikhtiar Uddin Bhuiyan ${ }^{1}$, Kamrul Hasan ${ }^{1}$, \\ Md Yousuf Ali ${ }^{1}$, Ahnaf Tahmid Arnab ${ }^{1}$ \\ ${ }^{1}$ Department of Government and Politics, Jahangirnagar University, Dhaka, Bangladesh \\ ${ }^{2}$ Sir Peter Mansfield Imaging Centre, University of Nottingham, Nottingham, UK
}

\section{Email address:}

siraj_sanwar@yahoo.com (Md. S. Siraj), Rebecca.Dewey@nottingham.ac.uk (R. S. Dewey), ikhtiar.bhuiyan@juniv.edu (Md. I. U. Bhuiyan), k.hasan@juniv.edu (K. Hasan), rahulmandalju44@gmail.com (Md. Y. Ali), ahnaf.stu2016@juniv.edu (A. T. Arnab)

${ }^{*}$ Corresponding author

\section{To cite this article:}

Md. Sanwar Siraj, Rebecca Susan Dewey, Md Ikhtiar Uddin Bhuiyan, Kamrul Hasan, Md Yousuf Ali, Ahnaf Tahmid Arnab. The Mental Health Act and Public Perception on Resource Allocation in Bangladesh. American Journal of Psychiatry and Neuroscience.

Vol. 9, No. 2, 2021, pp. 38-43. doi: 10.11648/j.ajpn.20210902.13

Received: March 19, 2021; Accepted: April 7, 2021; Published: April 13, 2021

\begin{abstract}
The Bangladesh government passed a new Mental Health Act in 2018, which formally came into effect on November 14. In order to decrease the significance and endurance of the hundred-year-old statute, the Lunacy Act of 1912, the government enacted the new Act by reformation. The Act is designed to ensure the provision of health services, the preservation of dignity, property rights and rehabilitation, and the general wellbeing of individuals suffering from diseases and disorders associated with mental health. The purpose of this study was to explore the influence of public opinions around mental health with regard to resource allocation by policy makers in Bangladesh. By reviewing mental health policy documents and the political literature on resource allocation in mental health, this study finds that despite the provisions of the Act, the lack of public support in mental health often discourages policymakers from allocating appropriate medical resources in mental health services. Since Bangladeshis generally perceive mental illness as a divine punishment apportioned by devil spirit or jinee, public support for mental health services is lacking. Consequently, Bangladeshi policy makers are discouraged from allocating the necessary resources and services in mental health. At the time of the COVID-19 pandemic in Bangladesh, the shortage of facilities and funds for mental health was acute, creating a huge burden on families of people with mental illness. In order to provide psychological and mental welfare services to its mentally ill and disorder-related patients, the government of Bangladesh must allocate the required resources in mental health.
\end{abstract}

Keywords: Mental Health, Mental Illness, Resource Allocation, Bangladesh

\section{Introduction}

Policy documents instruct healthcare providers in the provision of care for patients with mental illness. In 2018, the Bangladesh government passed a new Mental Health Act, which formally entered into force on November 14 (http://bdlaws.minlaw.gov.bd/act-details-1273.html). In order to decrease the significance and endurance of the hundredyear-old statute, the Lunacy Act of 1912, the government enacted the Act by reformation. The Act is designed to ensure the provision of health services, the protection of dignity, property rights and rehabilitation, and the general wellbeing of individuals suffering from diseases and disorders associated with mental health.

Bangladesh has a population of 165 million, which is equal to $2.1 \%$ of the world's total population [1]. According to the Bangladesh National Mental Health Survey (2018-2019), the prevalence of mental health disorders among adults aged 1899 is $16.8 \%$ and $13.6 \%$ for children aged 7 to 17 years [2]. A reported of $92.3 \%$ of adults and $94.5 \%$ of children diagnosed with mental health problems remain untreated [2]. In Bangladesh, similar to other low- and middle-income countries, the care of mental health patients is considered a lower priority by policy makers [3]. Bangladesh's government is legally obligated to provide basic healthcare 
facilities and essential logistical supplies to the public through publicly funded hospitals [4]. Delivering these services free of charge, or subsidized, to such a large population, presents the government with significant challenges [5]. As less than $2.5 \%$ of Bangladesh's gross domestic product (GDP) is spent on the health sector, the national budgetary allocation for healthcare is not adequate $[6,7]$. A significant proportion of the national budget is spent on the construction of hospital facilities and on the procurement of medical technology and equipment. Bangladesh regularly faces problems with widespread poverty, including low buying power and low adult literacy rates, malnutrition of newborn babies and mothers, overcrowding of publicly funded hospitals, lack of water, sanitation, and hygiene, and natural and environmental disasters [8]. Therefore, the government was forced to allocate funds and services to address the needs of the general population, including food, clothing, housing, education, and medical care [9]. As a result, healthcare services such as mental health have not been prioritized by policy makers in Bangladesh.

In 2000, the first official dengue fever outbreak in Bangladesh was recorded, having already been highly prevalent since 2019 [10]. Despite the occurrence of dengue fever, the outbreak identified a fragility in the national healthcare system in mid-2020 [8]. The government was forced to allocate much of the healthcare budget to addressing the spread of COVID-19, including vaccination services, following the first identification of the virus in the country on March 08, 2020. The number of mental health patients has risen further in the wake of the COVID-19 pandemic [11] due to the anxiety and depression generated by fear of infection, isolation due to rules imposed during lockdown periods, and maintaining physical distancing. Combined with inadequate access to mental healthcare services, the symptoms of anxiety and depression, acute or long-term post-traumatic stress disorders have been increasing in the general Bangladeshi population [12]. Thus, these pre-existing systemic healthcare deficiencies have been exacerbated by the multi-faceted effect of the COVID-19 pandemic. Although mental health laws like the Act entrust the government with the responsibility of establishing, maintaining, improving, and co-coordinating programs for patients with mental illness and disorders globally, in Bangladesh, mental health is underfunded and often ignored by legislators $[13,14]$. For example, only $0.5 \%$ of the overall health expenditure of the country is dedicated to improving mental health services [15]. The implementation of the Act alone will not cause significant improvements in the provision of treatment unless a mental health budget is properly allocated. Many Bangladeshis see mental illness as divine punishment, apportioned by demons, evil spirits or the jinee [16]. These perceptions underpin the lack of public support for mental health services. Such biases serve as a significant challenge to policy makers, making them less inclined to devote resources to mental health. This article aims to provide a summary of Bangladeshi mental health policy, to discuss the perceptions among the Bangladeshi public regarding mental health and to determine the impact of these opinions on legislation and resource allocation in mental health services.

\section{Methodology}

Mental health resource distribution is ignored in areas of concern to policy makers in Bangladesh. The goal of this research is to examine the impact of public views on mental health with regard to the allocation of resources by policy makers in Bangladesh. This research aims to examine why the distribution of mental health services is less of a concern for policy makers in Bangladesh by analyzing a handful of literature and policy articles.

\section{Major Stipulations of the Mental Health Policy}

The Mental Health Act of 2018 defines mental health as a normal state where each person is able to realize their abilities, live in accordance with normal life stresses, participate in positive and productive work and contribute in some way to their society (Section 2). As defined by the medical officer in charge (Section 2), the Act describes mental illness as a form of illness exclusive of drug addiction and mental impairment and outlines mental disorder as a variety of clinically recognized symptoms or habits, including mental disability and drug addiction, which are linked to various forms of physical and mental disorder, or both, and interfere with the normal physical or mental state, or both. Drug addiction is defined under the Act as the effects of physical and mental changes that are detrimental to a person as a consequence of the sudden cessation of daily substance use or consumption or after regular use (Section 2). The Act empowers the government of Bangladesh to establish and extend county-wide mental health facilities. Section 4 of the Act defines the provision of mental health services as the responsibility of the government. It involves undertaking activities across the country to broaden, develop, monitor and organize mental healthcare activities. This means that the government is responsible for the coordinated expansion and advancement of mental health programs for patients with mental illnesses and disorders. The purpose of the Act is to protect the health, property, dignity, education, and other rights of a person suffering from mental illness as governed by the laws (Section 6). It implies that the Act entrusts the government with the influence necessary to preserve the health of a person suffering from mental illness and associated problems, and to protect their property, education and other rights.

In order to provide treatment and services to a person suffering from mental illness, the government is entitled to establish mental healthcare facilities at any location in the country or establish separate departments or units of medical college hospitals or district hospitals (Section 7). In each 
psychiatric hospital or unit, separate arrangements can be set up for the treatment of drug addicts and psychiatric patients on trial or convicted. Furthermore, in each mental healthcare facility, a separate arrangement for the treatment of patients with minor problems can also be set up. It implies that under the law, the government is instructed to establish mental healthcare facilities or expand separate psychiatric departments/units in medical colleges or district hospitals. The government is directed to offer licenses to individuals who wish to establish and operate mental healthcare facilities that are privately run (Section 8). In addition to establishing publicly funded psychiatric hospitals or units, the Act promotes the private establishment of mental healthcare facilities by the government of Bangladesh.

\section{Mental Health Infrastructure and Facilities in Bangladesh}

In Bangladesh, the healthcare system is largely funded by a mixture of public and private organizations, with a small minority of facilities funded by non-governmental organizations (NGOs) and international development agencies (IDAs). Public hospitals predominantly provide patients with care free of charge or at subsidized rates, while private hospitals run mainly on a profit-making basis. Although affluent patients are usually treated at privately funded hospitals due to the reliably high standards of diagnosis, care, and treatment, the vast majority of poor and middle class Bangladeshis rely primarily on government (public) hospitals [8]. Bangladesh's public healthcare system is hierarchically organized. The Ministry of Health and Family Welfare (MOHFW) is at the top of the list and is responsible at the national level for formulating health policy, planning, and decision-making. The MOHFW comprises two divisions; the Division of Health Services (HSD) acts to make policy provisions on health-related issues, healthcare management, nursing care maintenance, health financing, etc., while the Division of Medical Education and Family Welfare (MEOFWD) works to make policy provisions on medical education and family planning for medical colleges and universities, the registration of births and deaths, etc. [17]. Under the MOHFW, the Directorate General of Health Services (DGHS) is the largest implementation agency for healthcare service delivery. When a new health program and intervention is to be implemented, the MOHFW seeks technical help from the DGHS.

The six-tier infrastructure under the DGHS generally provides healthcare services at the national, divisional, regional, sub-district, union, and ward levels [17]. Bangladesh is subdivided into eight divisional administrative units. Each division is divided into 64 districts, 492 subdistricts, and 4553 unions. Each union is further subdivided into nine wards, and finally each ward contains several villages, with the village being the lowest administrative unit. Until December 2016, there were some 40,977 wards comprising approximately 87,310 villages [18]. Hospitals and postgraduate medical education and training institutions offer specialized healthcare facilities at the national level. Specialized healthcare facilities at the tertiary level are mainly provided by hospitals located in Dhaka, the capital city of Bangladesh. There is one infectious disease hospital in each division and one or more medical college (s) at the divisional headquarters with their own hospital. These divisional hospitals effectively provide patients with tertiary healthcare services [19]. District hospitals, located at the district headquarters, and often with adjoining medical colleges, offer secondary level healthcare services. Subdistrict hospitals specialize in providing primary healthcare services. There is no sub-district hospital in the sub-district containing the district headquarters; instead, the district hospital offers the necessary primary care services. Rural health centers, union sub-centers, and union health \& family welfare centers (UHFWCs) offer health services at the union level (18). Union centers only provide outpatient facilities. Community Clinics (CCs; rural community-based health units) provide services at the ward level. A CC is intended to provide services for every 6,000 to 8,000 people in the region, with a total of 13,861 CCs nationwide [18]. These centers primarily provide basic and primary healthcare services, such as immunizations, treatment for common diseases such as pneumonia, fever, cough, etc., family planning, health education, and first aid, and serve as the first point of patient contact. Some CCs also provide maternity services through community-skilled birth attendants [18].

Vision 2021, the successful political manifesto of the Bangladesh Awami League in the 2008 national election, aimed to establish Bangladesh as a middle-income country by March 2021, when the country celebrates 50 years of independence. One condition of Vision 2021 is encouraging Bangladeshis to lead a healthy lifestyle. As mental health is an essential component of general well-being [20, 3], the Bangladeshi government will need to provide mental healthcare to those suffering from mental illness in order to achieve this goal for its citizens. The psychological conditions of anxiety and distress are on the rise among the general population both internationally and in Bangladesh $[21,22,11]$. There are no structured mental health services available in Bangladesh at either the primary or secondary levels, with such services being limited to tertiary hospitals and clinics located mostly in Dhaka [14]. Since only a few professionals in Bangladesh have specialized training in adolescent mental health services, the significant gap between the public need and the services available requires immediate attention [23]. Although there is a gradual increase in training and services addressing the need for psychiatric care, the vast majority of mental health patients, particularly those from poor and middle-income areas, have yet to benefit from such initiatives due to limited access [24]. This is because resource allocation in mental health is a low priority for policy makers in Bangladesh, evident in the allocation of only $0.5 \%$ of the country's total budget being allocated to improving mental health services. Conversely, in developing countries, budget allocation to mental health 
services is recommended to be in excess of 5\% [15].

The structures and facilities providing mental health services in Bangladesh are limited. Only two specialized psychiatric hospitals exist in the country. These include the National Institute of Mental Health (NIMH), which has 500 beds and is based in Dhaka [13], and Pabna Mental Hospital, also with 500 beds, located $162 \mathrm{~km}$ west of Dhaka. A total of 56 public hospitals have psychiatric outpatient facilities, along with 504 inpatient beds [13]. In Bangladesh, there are approximately 260 psychiatrists (approximately 0.16 per 100,000 population), as well as 700 nurses $(0.4$ per 100,000$)$ and 565 psychologists $(0.34$ per 100,000$)$ who provide specialty mental healthcare. Almost all specialists are concentrated in Dhaka and the surrounding major urban areas. In and around Dhaka, the density of psychiatric beds is five times greater than that of the rest of the country [24], although $63 \%$ of the population still lives in rural areas [25]. There is a lack of qualified healthcare professionals to provide mental health patients with psychosocial interventions [13]. A limited amount of essential psychotropic medication is available at general hospitals, but no injectable antipsychotic drugs, and insufficient supplies of other medicines [13]. Nationally, Bangladesh has 31 community-based inpatient psychiatric units, a 16-bed hospital with forensic inpatient units, 72 hospitals providing residential care facilities comprising 3,645 beds (e.g. homes for the destitute, inpatient detoxification centers and homes for people with mental disabilities), 69 outpatient mental health facilities, and 20 hospitals with adolescent mental health facilities $[13,24]$.

\section{Public Perception of Mental Health Resource Distribution}

This article was intended to explore policy makers' perceptions in terms of mental health resource allocation, and investigate why mental health resource allocation is less of a priority for policy makers. Corrigan \& Watson suggest that the interpretation of the findings depends on the assumption that policy makers tend to allocate money to those programs that are more likely to receive public support [26]. Policy makers are less likely to allocate money if they perceive that a project lacks public support. A cause lacking public support in turn implies that the severity and burden created by an absence of support is less likely to be recognized by the general public. Why do particular causes lack support? The likely explanation is that Bangladeshis, who mostly inhabit the rural areas of the country, generally regard mental illness as divine punishment associated with abduction by demons, evil spirits and jinee [16]. Despite psychological therapies may be beneficial to individuals who are suffering from mental illnesses, however, most Bangladeshis consider that treating people suffering from mental illness is an unnecessary health intervention. Mental illness has always baffled scholars, and ultimately the general masses, being enigmatic and intangible. It is possible to draw on philosophy in the attempt to understand the apathy, and sometimes abhorrence, the Bangladeshi public feel towards the concept of mental illness. Plato delves deep inside the philosophical interpretation of death and madness in the texts of Phaedo and Phaedrus. The lack of a clear reason for the existence of life, may have led Plato, unlike the sophists, to equate philosophy with the maddening will to die for reason. Therefore, in Plato's words,' madness can be supposed to coincide with reason, giving serious importance to understanding the metaphysical metaphor [27]. Like other early Greek philosophers, Philo refers to insanity as death because it causes the mind to die. Further, he describes the mind as the most noble part of the human body [27]. Psychoanalysts such as Sigmund Freud and Carl Jung, and postcolonial theorists such as Jacques Derrida, Jacques Lacan and Michel Foucault, have sought to grasp the metaphysical basis of mental illness and its influence on social apparatus in the 19th and 20th centuries. Freud argued that people's actions were always derived from the 'unconscious' mind [28], while Jung identified mental illness as extreme reactions to emotional events seeded in the unconscious [29]. For example, Foucault believed that the development of medical science was more objective for people with mental illness [30]. He believed that mental illness had previously been considered a normal state of mind, but that subsequently, society had developed values for what were considered the parameters of a 'normal' psyche, deeming anyone straying outside those normal parameters to be mentally ill. The mentally ill were then locked up in closed quarters, and through the ministrations of doctors and asylums became transformed into objects of fear and abhorrence. Hegel characterized insanity in the human mind, Nietzsche associates thoughts with insanity while Pascal describes insanity as being synonymous with thoughts. Rousseau stated that insanity signified a high level of intelligence [31]. Thinkers of all ages have deliberated 'madness', 'insanity' and mental illness. Although many of the traditional theories and superstitions surrounding mental illness act in opposition to the progress of neuropsychology and sociobiology, Bangladeshi communities still find refuge in these irrational superstitions. A prominent Bengali poet once wrote of the time he spent in an asylum; some would call me insane at night when I was in the Ezra hospital, Paramesh and Uma Dasgupta would come, ready with choppers. I told them: don't you see 'asylum' written on the door? If you kill and eat my meat, every night you too will become $\operatorname{mad}[32,33]$. Analysis of this literary text unearths the roots of repulsion, dogma and disdain held by society for individuals who are psychologically ill. As such, mental illness and disorders of the mind are attributed great stigma by the general population.

Ngui others describe a lack of public understanding of mental health conditions, combined with an insufficient public understanding of the causes of mental illness that have resulted in little expectation on policy makers to consider mental health [34]. Mental illness and associated problems account for approximately $17 \%$ of the total disease burden in Bangladesh, but the attention given by policy makers remains 
low. Mental health is still largely neglected, despite various charitable agencies and NGOs in Bangladesh with remits in the areas of chronic non-communicable diseases [3]. Why is resource allocation given the lowest priority by policy makers in Bangladesh? Corrigan and Watson's argument attributed this degree of apathy to the general public's inability to understand the need for increased spending in the field of mental health [26]. Corrigan and Watson provide evidence for this in the form of survey results that found public support for the allocation of financial resources to mental health to be poor in comparison to support for other government-sponsored programs in the same year, with $60 \%$ of respondents opting to spend more on environmental conservation and $70 \%$ advocating funding for general healthcare services [26]. Why does the public endorse funding environmental issues and general healthcare programs over mental health? This view relates to the process of prioritizing the allocation of resources, when those resources are finite and must be allocated at a national scale. The thought process relates to what degree of resource do mental health services require, and how large is this as a proportion of the total resources the government must allocate in Bangladesh? It is reasonably straightforward for policy makers to allocate resources if the necessary funds are available [35], and typically funds are allocated according to demand [26]. If resources are scarce, policy makers typically distribute funds on the basis of public expectation [26]. The lower expectation of the public that mental health will receive support discourages Bangladeshi politicians from allocating funding to this field.

\section{Conclusion}

What is the underlying social tension that the Act was intended to solve? The Act was formulated to address the issue of how the government should distribute the requisite services for mental health services. Public health laws usually act to provide a legal institutional structure that empowers the government to establish a logical and transparent resource distribution process in healthcare. Public healthcare legislation such as the Act is meant to allow the government to use their legal authority to distribute resources such that patients with mental illness receive the care required. The Act, however, lacks any mechanism for resource distribution for inpatient care of mental illness. The lack of social care resources for mental illness places undue pressures on patients and their families. The lack of a resource distribution system also places a significant burden on healthcare professionals in terms of determining how scarce medical services should be allocated and to whom [8]. The COVID-19 pandemic has further exacerbated these differences. The Act therefore requires major improvements to the provisions on resource distribution, and the addition of parliamentary sanction on the distribution of scarce mental health services in the country. While the Act provides a legislative structure to protect the health service and human rights provisions for patients with mental illness, these policies must protect patients with mental illness and disorders from violence, neglect and prejudice, and provide them with the treatment they need [34]. Policies must be fair and transparent, and must provide social care and legal security to those living with psychological ill-health [34].

\section{Declaration Statement}

The authors declare that they have no conflict of interest.

\section{References}

[1] Worldometer. Bangladesh Population (2021) - Worldometer [Internet]. Woldometer. 2021 [cited 2021 Jan 23]. Available from: https://www.worldometers.info/world-population/bangladeshpopulation/.

[2] MOHFW. Minister of Health releases first findings of National Mental Health Survey [Internet]. WHO. 2019 [cited 2021 Jan 23]. Available from: https://www.who.int/bangladesh/news/detail/27-11-2019minister-of-health-releases-first-findings-of-national-mentalhealth-survey.

[3] Islam Anwar \& Biswas Tuhin. Mental Health and the Health System in Bangladesh: Situation Analysis of a Neglected Domain. American Journal of Psychiatry and Neuroscience [Internet]. 2015; 3 (4): 57-62. Available from:

http://www.sciencepublishinggroup.com/journal/paperinfo. aspx?journalid $=653 \&$ doi $=10.11648 /$ j.ajpn.20150304.11.

[4] GoB. The Constitution of the People's Republic of Bangladesh [Internet]. Bangladesh: Legislative and Parliamentary Affiars Division; 1972. Available from: http://bdlaws.minlaw.gov.bd/act-367.html.

[5] GoB. Health Bulletin 2017 [Internet]. Government of Bangladesh. 2018 [cited 2020 Sep 2]. Available from: https://dghs.gov.bd/index.php/en/home/4364-health-bulletin2017.

[6] Islam A. Health System in Bangladesh: Challenges and Opportunities. American Journal of Health Research [Internet] 2014; 2 (6): 366-74. Available from: http://www.sciencepublishinggroup.com/journal/paperinfo.asp $\mathrm{x}$ ?journalid=656\&doi=10.11648/j.ajhr.20140206.18.

[7] World Bank. Current health expenditure (\% of GDP) [Internet]. The World Bank Group. 2017 [cited 2020 Aug 21]. Available from: https://data.worldbank.org/indicator/SH.XPD.CHEX.GD.ZS.

[8] Siraj MS, Dewey RS, Hassan ASMFU. The Infectious Diseases Act and Resource Allocation during the COVID-19 Pandemic in Bangladesh. Asian Bioethics Review. 2020.

[9] GoB. The Constitution of the People's Republic of Bangladesh | 15. Provision of basic necessities [Internet]. GoB 1972 [cited 2021 Jan 23]. Available from: http://bdlaws.minlaw.gov.bd/act-367/section-24563.html.

[10] Mamun MA, Misti JM, Griffiths MD, Gozal D. The dengue epidemic in Bangladesh: risk factors and actionable items. The Lancet. 2019. 
[11] Islam MS, Ferdous MZ, Potenza MN. Panic and generalized anxiety during the COVID-19 pandemic among Bangladeshi people: An online pilot survey early in the outbreak. Journal of affective disorders [Internet]. 2020 Nov 1; 276: 30-7. Available from: https://linkinghub.elsevier.com/retrieve/pii/S01650327203244 60.

[12] Banna MH Al, Sayeed A, Kundu S, Christopher E, Hasan MT, Begum MR, et al. The impact of the COVID-19 pandemic on the mental health of the adult population in Bangladesh: a nationwide cross-sectional study. International Journal of Environmental Health Research [Internet]. 2020 Aug 2; 1-12. Available from: https://www.tandfonline.com/doi/full/10.1080/09603123.2020 1802409

[13] WHO. Bangladesh WHO Special Initiative for Mental Health Situational Assessment. 2020. [cited 2021 Jan 29]. Available from https://www.who.int/docs/default-source/mentalhealth/special-initiative/who-special-initiative-country-report--bangladesh---2020.pdf?sfvrsn=c2122a0e_2.

[14] Hossain MD, Ahmed HU, Chowdhury WA, Niessen LW, Alam DS. Mental disorders in Bangladesh: A systematic review. BMC Psychiatry. 2014; 14 (1): 1-8.

[15] Bangladesh Post. Declining mental health: Invest more in mental health services. Bangladesh Post. 2020 Oct 09. [cited 2021 Jan 29]. Available from https://bangladeshpost.net/posts/declining-mental-health44293.

[16] Islam R. Foreign report Psychiatry in Bangladesh. Psychiatric Bulletin. 1993; 17: 492-4.

[17] GoB. Health Bulletin 2019 [Internet]. 2020 [cited 2021 Jan 25]. Available from: www.dghs.gov.bd.

[18] GoB. Health Bulletin [Internet]. 2017 [cited 2021 Jan 25]. Available from: www.dghs.gov.bd.

[19] GoB. Health Bulletin 2016 [Internet]. 2016 [cited 2021 Jan 25]. Available from: www.dghs.gov.bd.

[20] Kolappa K, Henderson DC, Kishore SP. No physical health without mental health: Lessons unlearned? [Internet]. Vol. 91, Bulletin of the World Health Organization. World Health Organization; 2013 [cited 2021 Jan 26]. p. 3-3a. Available from: http://www.un.org/en/sc/documents/resolutions/.

[21] Salari N, Hosseinian-Far A, Jalali R, Vaisi-Raygani A, Rasoulpoor S, Mohammadi M, et al. Prevalence of stress, anxiety, depression among the general population during the COVID-19 pandemic: A systematic review and meta-analysis. Globalization and Health. 2020.

[22] Wang C, Pan R, Wan X, Tan Y, Xu L, McIntyre RS, et al. A longitudinal study on the mental health of general population during the COVID-19 epidemic in China. Brain, Behavior, and Immunity. 2020.

[23] Corrigan PW, Watson AC, Warpinski AC, Gracia G. Stigmatizing attitudes about mental illness and allocation of resources to mental health services. Community Mental Health Journal. 2004; 40 (4): 297-307.

[24] WHO. WHO-AIMS REPORT ON MENTAL HEALTH SYSTEM IN BANGLADESH. 2007. [cited 2021 Jan 29]. Available from https://apps.who.int/iris/handle/10665/206149.

[25] The World Bank. Rural population (\% of total population) Bangladesh | Data [Internet]. The World Bank. 2019 [cited 2021 Jan 29]. Available from: https://data.worldbank.org/indicator/SP.RUR.TOTL.ZS?locati ons $=\mathrm{BD}$.

[26] Corrigan PW, Watson AC. Factors that explain how policy makers distribute resources to mental health services [Internet]. Vol. 54, Psychiatric Services. Psychiatr Serv; 2003 [cited 2021 Jan 27]. p. 501-7. Available from: https://pubmed.ncbi.nlm.nih.gov/12663837/.

[27] Güven F. Madness and death in philosophy. Madness and Death in Philosophy. 2005. 1-220.

[28] Berthold-Bond D. Hegel, Nietzsche, and Freud on Madness and the Unconscious. The Journal of Speculative Philosophy. 1991; 5 (3): 193-213.

[29] Koss-Chioino JD. Jung, Spirits and Madness: Lessons for Cultural Psychiatry. Transcultural Psychiatry. 2003; 40 (2): 164-80.

[30] Foucault M. Madness and Civilization: A History of Insanity in the Age of Reason, trans. Richard Howard (New York: Pantheon, 1965). 1965

[31] Felman S. Madness and the Literary: Toward the Question of the Book. Writing and Madness: Literature/Philosophy/Psychoanalysis. 2003. p. 251-5.

[32] Majumdar B. Poetry Written in the Hospital. Kabitirtha; 2003. $64 \mathrm{p}$.

[33] Chakravarty P. Madness and the art of a Bengali poet. Scroll. in. 2017.

[34] Ngui EM, Khasakhala L, Ndetei D, Roberts LW. Mental disorders, health inequalities and ethics: A global perspective. International Review of Psychiatry. 2010; 22 (3): 235-44.

[35] Skitka LJ, Tetlock PE. Allocating scarce resources: A contingency model of distributive justice. Journal of Experimental Social Psychology. 1992 Nov 1; 28 (6): 491522. 